\title{
The Problems and Countermeasures of College Chinese Teaching Under the Background of Liberal Education
}

\author{
Shuhong Sun \\ Changchun Vocational Institute of Technology, Changchun, China \\ sunshuhongcc@126.com
}

Keywords: liberal education, higher vocational colleges, college Chinese, teaching reform

\begin{abstract}
As a kind of educational concept, liberal education has gradually been accepted and approved by Chinese educational circles. As an integral part of education, liberal education adheres to the educational concept of "complete man" desired by the society and provides a new opportunity for the current reform and development of college Chinese education. Only by fully recognizing the great significance of higher vocational college Chinese, finding out existing problems in Chinese teaching in higher vocational colleges and perfecting college Chinese teaching reform measures can college Chinese go out of the dilemma and return to the road of benign development.
\end{abstract}

\section{Introduction}

Along with the increasing demands of the society for high-quality and all-round talents, especially after the advancement of "Scientific Outlook on Development", to prevent higher vocational education from becoming utilitarian and instrumental, higher vocational colleges have begun to implement liberal education with the purpose of cultivating full and complete men. As one of the numerous compulsory courses among higher vocational colleges, college Chinese plays an incomparable key role to other courses in liberal education of higher vocational colleges. The Chinese course has gradually established a core position in liberal education of higher vocational colleges.

\section{The Role of College Chinese in Liberal Education}

\subsection{Traditional culture can cultivate students' noble morality}

"Morality supremacy" is an important characteristic of traditional Chinese culture. Moral awareness penetrates every aspect of Chinese culture and life. Likewise, the obedience to the code of ethics makes many people with lofty ideals risk death to pursue a just cause resolutely at critical moments. In college Chinese course, this kind of cultural tradition, i.e., to emphasize morality but be little actual benefits, still has a moralizing effect on young people who are living in a market economy environment today. It can help them establish a correct outlook on life and value ${ }^{[1]}$.

\subsection{The sense of worry and responsibility can promote students' sense of social responsibility}

The Chinese nation has gone through tribulations. The sense of worry has run through the course of history, which made loyal officials and virtuous men in past dynasties struggle hard to distinguish themselves. It can inspire young students today to seek benefits for people and firmly set up the thought to serve the country and realize the great rejuvenation of the Chinese nation.

\subsection{The spirit of struggle can inspire students to hone a tenacious will power}

The concept of “persevering” struggle emerged as early as in the pre-Qin books. This kind of persevering and tenacious spirit encourages the Chinese nation not to surrender to hardships and setbacks and not to be conquered or overwhelmed by any invasion or oppression, but to inherit and carry forward the splendid tradition and culture of the Chinese nation unyieldingly ${ }^{[2]}$. Owing to this, 
the Chinese civilization managed to survive and deposit over thousands of years and became a miracle in the history of world civilization.

\section{Existing Problems in College Chinese Teaching}

\subsection{The attention received is insufficient}

The position of college Chinese teaching is increasingly marginalized. Many colleges no longer attach importance to Chinese teaching, but constantly compress academic hours of Chinese teaching and dismiss it as an elective course. As a result, the quality of Chinese teaching goes from bad to worse. By and by, Chinese teaching is faced with the crisis of being cancelled. The administrator regards college Chinese as an auxiliary tool of professional courses, believing that college Chinese is designed to train students' writing skills and knowledge about literary form required by employment and to serve professional courses. Students can choose not to learn pure ideological content, for example, ancient-style proses. Secondly, the teaching assessment of college Chinese is improve ${ }^{[3]}$. College Chinese is always assessed semester as a non-examination subject. Students mainly fix their eyes upon examination subjects and seldom put efforts on non-examination subjects.

\subsection{The goal orientation is inaccurate}

The goal orientation of higher vocational Chinese is to "emphasize knowledge but be little ability", "emphasize instrumentalism but be little humanism". There is a lack of aesthetic, moral and innovative factors. First of all, the educational goal of college Chinese still lays great emphasis on pure accumulation of knowledge, while neglects the development and formation of abilities. Secondly, the educational goal of college Chinese tends to be self-enclosed and lacks interactions with other subjects. College Chinese teaching should not only edify students' thinking, but also pay attention to letting students develop good accomplishment and personality. To make students grow and become talents, the latter effect is more noticeable and direct. The educational goal of college Chinese should constantly explore methods and paths to improve students' personality and humanistic quality through Chinese teaching ${ }^{[4]}$.

\subsection{The educational mode is unscientific}

The core spirit of quality-oriented education is to face all students and promote students' all-round and personality development, give play to their subjective spirit and foster a real person, rather than a successful test-taking machine. China has long been dominated by exam-oriented education, which makes students very utilitarian. The professional education is very narrow. The cultural edification is weak. The constraint of commonality is very strong. Consequently, the cultivation of talents suffers many obstacles. In terms of educational mode, higher vocational colleges give priority to professional courses. The Chinese course is established as an auxiliary course. The quality-oriented education awareness of college Chinese is weak. The administrator is indifferent because the employing companies higher vocational colleges are faced with focus on students 'specialized operating skills and practical experience at work ${ }^{[5]}$. To make the graduates satisfy the employing companies when hunting for a job, the administrator treats college Chinese with indifference consciously when setting curricula. As the Chinese course is not valued by the college, both the curriculum setting and fund appropriation for teachers are marginalized.

\section{Strategies to Optimize College Chinese Teaching}

\subsection{To position college Chinese teaching clearly}

College Chinese teaching should first change the thought, enhance the awareness of competent departments, teachers and students of the college, elevate college Chinese to the height a professional compulsory course, position college Chinese clearly, combined with the ultimate training goal and training requirements for talents in colleges, according to the talent training plan 
of each college. Only by positioning clearly can we truly solemnize the assessment, appraisal and other evaluation systems. Meanwhile, during the teaching reform of college Chinese, we should clarify the teaching goal and break down the goal, to make each teaching process have a clear teaching direction and teaching goal. Reconstructing the teaching goal of college Chinese allows us to establish a workable goal for its reform. Since college Chinese is multi-functional, different colleges with different subjects, even different majors in the same college must position the teaching goal of college Chinese according to their own needs, break through the original single, instrumental and technical thinking mode and establish it from basic, comprehensive and tasteful aspects. Following this train of thought, we believe that the teaching goal of college Chinese is to expand and strengthen students' Chinese foundation, intensify their abilities, such as language expression, reading comprehension, logical thinking, aesthetic appreciation and writing ability, tap their intelligence, enhance literary accomplishment and cultivate their perception, imagination and creativity.

\subsection{To establish an open teaching mode}

"Open teaching" requires teachers to play down the "sample" nature of text book in the teaching process and open up the teaching content. In the context of modern educational informationization, teachers must gradually form the concept of greater education, break the barrier between disciplines, make single teaching and research activities into comprehensive classroom teaching and research activities, change "teaching textbooks" into "using textbooks", blur the demonstrativeness of textbook, stress its reference function, emphatically strengthen the integration of educational concept, learning content, teaching technology and teaching resources, deal with the fusion between fundamental knowledge and up-to-date information technology and the fusion between fundamental content and developmental content, facilitate the widespread application of information technology in teaching and change the traditional way of teaching management. College Chinese teaching needs to be "tailored", "dare to jump out of the textbook", create new learning scenarios and let students learn to achieve differentiated learning goals using dialectical thinking. Students choose the order of learning, time distribution, amount of practice and content extension, etc., according to their actual conditions, while teachers are mainly responsible for real-time monitoring, coaching or direction ${ }^{[6]}$.

\subsection{To construct the teaching staff and textbook}

The teaching reform requires improving the construction of teaching staff. College Chinese teaching must strengthen the cultivation of young teachers, establish an incentive effect accordingly, encourage them to pursue further studies, offer them more opportunities, fully mobilize young teachers' learning initiativeand teaching creativity, strengthen the discipline construction of college Chinese, inspire teachers to develop school-based curricula and school-based textbooks for college Chinese and incorporate research on public teaching of college Chinese into the scientific research agenda of colleges. Only in doing this will college Chinese truly become an important basic course in school education. With respect to textbook construction, it is necessary to investigate the actual needs of students and avoid selecting too many writings in classical Chinese. The textbooks must encompass something plain and pellucid favored by students, thus inspiring their passion for college Chinese.

\section{Conclusion}

In a nutshell, as far as students are concerned, college Chinese carries on its shoulders the heavy burden of improving their Chinese literacy and increasing their overall humanistic quality. As far as culture is concerned, college Chinese undertakes the solemn mission to disseminate outstanding ancient and modern cultural heritages at home and abroad. Thus, its importance is self-evident. During the current transformation and development of colleges, we must exploit the advantages of college Chinese and play a unique and irreplaceable role in training application-oriented, technology-based, innovative and interdisciplinary talents. 


\section{References}

[1] Wu Tingting, The Highlight of Human Spirit and the Building of Chinese Accomplishment--the Culture Expectation of College Chinese Education from the Nature of College Chinese [J], Academic Exploration, 2012(11).

[2] Chen Shaozhi, The Trend and Reform of Chinese Teaching in Local Colleges in the New Era [J], China University Teaching, 2014 (11):69-72.

[3] Diao Liying, Analysis of the Existing State of College Chinese Teaching and Exploration of the Teaching Reform in Vocational Colleges [J], Journal of Suzhou Vocational University, 2006 (2): 31-34.

[4] Peng Zhenyu, The Goal, Content and Realization Path of Liberal Education in Higher Vocational Colleges [J], Vocational \& Technical Education Forum. 2007, (14): 11-15.

[5] Yang Shaobin, Reflection on the Teaching Reform of College Chinese [J], Journal of Hubei University of Education, 2010 (05):103-105.

[6] Zhao Yufang, On the Teaching Reform of College Chinese in Universities [J], Journal of Changzhou Vocational College of Information Technology, 2011(01). 